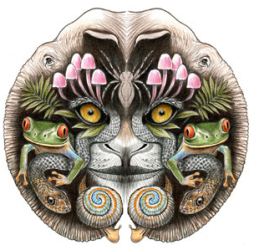

ISSN

Online 0974-7907

Print 0974-7893

OPEN ACCESS

\title{
BIOLOGY, BEHAVIOUR AND FUNCTIONAL RESPONSE OF CYDNOCORIS GILVUS BRUM. (HETEROPTERA: REDUVIIDAE: HARPACTORINAE) A PREDATOR OF TEA MOSQUITO BUg (HELOPELTIS ANTONII SigN.) ON CASHEW IN INDIA
}

\author{
K.K. Srikumar ${ }^{1}$, P.S. Bhat ${ }^{2}$, T.N. Raviprasad ${ }^{3}$ \& K. Vanitha $^{4}$ \\ 1,2,3,4 Department of Entomology, Directorate of Cashew Research, Puttur, Dakshina Kannada, Karnataka 574202, India \\ ${ }^{1}$ sreeku08@gmail.com (corresponding author), ${ }^{2}$ pshivarama59@gmail.com, ${ }^{3}$ tnrprasaad@gmail.com, \\ ${ }^{4}$ vanis102@gmail.com
}

Abstract: Helopeltis spp. (Hemiptera: Miridae) are major sucking pests of cashew (Anacardium occidentale L.) in India. Cydnocoris gilvus Brum. (Heteroptera: Reduviidae: Harpactorinae) is recorded as a potential predator of Helopeltis spp. Biology, mating behaviour and functional response of $C$. gilvus were studied by rearing in the laboratory (temperature $26-28{ }^{\circ} \mathrm{C}$; relative humidity $89-94 \%$ ) with wax moth, Galleria mellonella, larvae. Based on laboratory rearing, the fecundity was 56.33 eggs in 8.67 batches per female. The average stadial period was 37.3 days, with a maximum of 11 days for $V$ instar and a minimum of 4.5 days for III instars. C. gilvus took 45.5 days to complete a generation. The innate capacity of natural increase was 0.07 with a gross reproduction of 67.8 females per female. The adult exhibited a pin and jab mode of predation in a sequence of actions. The sequential action of mating comprised arousal (1.32 $\mathrm{min})$, approach (12.30 $\mathrm{min})$, riding over (140.48 $\mathrm{min}$ ) and copulation (85.40 $\mathrm{min}$ ). The predator responded to increasing prey density by killing more prey than at lower prey densities

Keywords: Anacardium occidentale, developmental stages, Galleria mellonella, Helopeltis antonii, predator.
Cashew (Anacardium occidentale L.) is a native of Brazil, and it was introduced into the western coast of India by Portuguese travelers during the $16^{\text {th }}$ century. India's share in world cashew area is $22.50 \%$ and the share in world cashew production is $20.74 \%$ (DCR 2011). Cashew is presently grown in an area of 0.982 million hectares with an annual production of about 0.728 million tonnes of raw cashewnuts in the country (DCCD 2013). Infestation by insects has been identified as a major factor responsible for low productivity in cashew (Sundararaju 1993). The main insect affecting cashew is the Tea Mosquito Bug (TMB), Helopeltis antonii Signoret (Hemiptera: Miridae). Both nymphs and adults damage tender shoots, inflorescence, immature nuts and apples at various stages of development, resulting in a yield loss of $30-50 \%$ (Devasahayam \& Nair 1986).

DOI: http://dx.doi.org/10.11609/JoTT.03815.5864-70 | ZooBank: urn:Isid:zoobank.org:pub:46BCC1B1-91E6-4EA5-82F6-A16426C2CFDE

Editor: Renkang Peng, Charles Darwin University, Darwin, Australia

Date of publication: 26 June 2014 (online \& print)

Manuscript details: Ms \# 03815 | Received 15 October 2013 | Final received 23 May 2014 | Finally accepted 02 June 2014

Citation: Srikumar, K.K., P.S. Bhat, T.N. Raviprasad \& K. Vanitha (2014). Biology, behaviour and functional response of Cydnocoris gilvus Brum. (Heteroptera: Reduviidae: Harpactorinae) a predator of Tea Mosquito Bug (Helopeltis antonii Sign.) on cashew in India. Journal of Threatened Taxa 6(6): 5864-5870; http:// dx.doi.org/10.11609/JoTT.03815.5864-70

Copyright: @ Srikumar et al. 2014. Creative Commons Attribution 4.0 International License. JoTT allows unrestricted use of this article in any medium, reproduction and distribution by providing adequate credit to the authors and the source of publication.

Funding: Supported by ICAR network project 'ORP on management of sucking pests of horticultural crops' through IIHR (Indian Institute of Horticultural Research) Competing Interest: The authors declare no competing interests.

Acknowledgements:We are very thankful to Indian Council of Agricultural Research, Govt. of India, for financial assistance (OPR on management of sucking pest of horticultural crops). The authors are grateful to the Director, Directorate of Cashew Research for institutional facilities. Our thanks are also due to Dr. Dunston P. Ambrose, Entomology Research Unit, St. Xavier's College, Palayamkottai, for morphologically identifying C. gilvus.
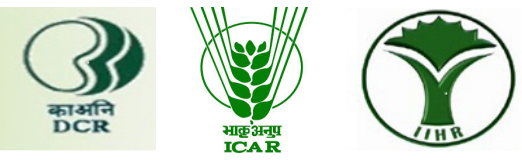
Reduviids (Hemiptera: Reduviidae) are recorded as potential natural predators of Helopeltis spp. on cashew (Devasahayam \& Nair 1986; Stonedahl 1991; Sundararaju 1996). Five species of reduviids, viz., Sycanus collaris Fab., Sphedanolestes signatus Dist., Endochus inornatus Stal, Irantha armipes Stal and Occamus typicus Dist., were reported as predators of Helopeltis antonii on cashew in India (Sundararaju 1984). E. inornatus was reported to feed on 20 individuals of $H$. antonii per day in cashew plantations (Sundararaju 1984; Devasahayam \& Nair 1986). Vennison \& Ambrose (1990) accounted for the significance of $S$. signatus in controlling Helopeltis spp. The biological control programme against Helopeltis spp. using reduviids has been reported from Southeast Asia and Pacific region (Rao et al. 1971).

Reduviids can be successfully used as effective biological control agents of important agricultural pests (Ambrose 2003; Sahayaraj et al. 2006). Biological parameters were reported for Rhynocoris kumarii Ambrose and Livingstone (Ambrose 2000), Sphedanolestes minusculus Berg. (Ambrose et al. 2006), Endochus migratorius Dist. (Ambrose et al. 2007), S. himalayensis Dist., S. signatus Dist. (Vennison \& Ambrose 1990) and S. variabilis Dist. (Ambrose et al. 2009). Although the biologies of a few species of Oriental reduviids are known, there are still plenty of other species to be explored (Sahayaraj 2012).

During the survey for natural predators of Helopeltis spp. in cashew plantations we recorded Cydnocoris gilvus Burmeister (Heteroptera: Reduviidae: Harpactorinae). Earlier, the prey mediated feeding response of $C$. gilvus was reported and it is described in the checklist of Indian assassin bugs (Venkatesan et al. 1997). The knowledge on bioecology, behaviour, and pest suppression efficacy of any organism is a prerequisite for its utilization as a biological control agent. Hence, we reared $C$. gilvus in the laboratory using wax moth, Galleria mellonella L. (Lepidoptera: Pyralidae), larvae as prey, and examined its biology, behaviour and the functional response towards its natural prey, Helopeltis antonii.

\section{MATERIAL AND METHODS}

Laboratory culture of $\boldsymbol{C}$. gilvus: The nymphs of C. gilvus were collected from cashew plantations of Directorate of Cashew Research (DCR), Puttur $\left(12.45^{\circ} \mathrm{N}\right.$ \& $75.4^{\circ}$ E; elevation $90 \mathrm{~m}$ ) in Karnataka State, southern India. They were reared in glass rearing bottles $(500 \mathrm{ml}$ capacity) using larvae of wax moth, under laboratory conditions (temperature $26-28{ }^{\circ} \mathrm{C}$; relative humidity 89-94\%). The virgin males and females that emerged in the laboratory were allowed to mate in glass rearing bottles. Only adults reared in the laboratory were used in the experimental studies.

The containers were carefully examined at regular intervals to record the number of eggs laid. Ejection of spermatophore capsules by mated females confirmed successful copulation. The eggs laid were allowed as such to hatch in the same bottles, which were kept over wet cotton swabs for maintaining optimum humidity (85\%). The cotton swabs were changed periodically in order to prevent fungal attack. Mated females were maintained individually in order to record the number of batches of eggs and the number of eggs in each batch. Twentyfive newly hatched nymphs were separated soon after eclosion and reared individually with first and second instar (5-6 mm) larvae of wax moth. As the nymphal development advanced the fourth and fifth instar larvae (10-15 mm) of the wax moth were supplied.

We observed eclosion, fecundity, hatchability, ecdysis, nymphal mortality, adult emergence, sex ratio and adult longevity from the adults that emerged in the laboratory for two generations. The life table parameters were obtained according to the methods of Atwal \& Bains (1974). Observations from hatching of eggs till the emergence and death of adults were made daily, which provided the values for a life table (Ix).

Predatory behaviour of $\boldsymbol{C}$. gilvus: Predatory behaviour of $C$. gilvus towards wax moth larvae and $H$. antonii adults was observed in a span of 24 hours. The extent of juvenile cannibalism in C. gilvus was also recorded.

Mating behaviour of $\boldsymbol{C}$. gilvus: The mating behaviour of sex starved $C$. gilvus was studied in laboratory conditions. The time taken for the sequential acts was observed.

Laboratory mass culture of $\boldsymbol{H}$. antonii: The $\boldsymbol{H}$. antonii gravid females were collected from the cashew plantations of DCR. They were allowed to lay eggs in the laboratory on potted cashew seedlings, which were confined in perforated tubular cages $(30 \times 7.5 \mathrm{~cm})$ made from transparent polyester film (thickness 175 micron). The respiratory processes of eggs projecting from the surface of the bark were indicative of the presence of eggs. Immediately after hatching, the nymphs were transferred into nymphal rearing cages (size: $15 \times 15 \times 20$ $\mathrm{cm}$ and thickness: 18 gauge) developed by Sundararaju \& John (1992). Nymphal rearing cages consisted of four glass vials of $5 \mathrm{ml}$ capacity fixed on a small aluminum stand with a handle of $15 \mathrm{~cm}$ height fixed at the centre. A tender cashew shoot was kept erect inside each vial filled with water and the opening of the vial was closed with wet absorbent cotton. Every third day another 
aluminum stand along with four fresh tender shoots was placed adjacent to the already existing aluminum stand without transferring/disturbing the nymphs feeding on the shoots kept on the previous day. In the rearing cage, two side provisions were fixed with cloth sleeve in order to facilitate the removal of adults after final moulting

Functional response: Laboratory raised and starved for $24 \mathrm{~h}$ adults of $C$. gilvus were used in this experiment. The functional response was assessed separately at four different prey densities viz., 1,2,4 and 8 prey/predator of its natural prey, $H$. antonii for five days in rearing glass bottles $(500 \mathrm{ml})$. Six replicates were made for each category. At $24 \mathrm{hr}$ interval the number of prey killed was recorded and the prey number was maintained constant by the introduction of fresh prey throughout the experiment. "Disc" equation of Holling (1959) $Y^{\prime}=\alpha$ Tt-by $X$ was used to describe the functional response of C. gilvus to $H$. antonii.

Where

\section{$\mathrm{X}=$ Prey density}

$Y=$ Total number of prey killed in given period of time $(\mathrm{Tt})$

Tt $=$ Total time in days for which prey was exposed to the predator

$b=$ Handing time in days

$\alpha=$ Rate of discovery per unit of searching time $(y / x$ / Ts)

$\mathrm{x} / \mathrm{y}=$ Attack ratio

\section{Ts $=$ Searching time in days}

Linear regression analysis was used to explore the relationship between the prey density and number of prey attacked, searching time and attack ratio.

\section{RESULTS}

Biology: Cydnocoris gilvus laid broadly oval, orange yellow coloured eggs in batches on the bottom of the rearing bottles, each egg vertically glued to the substratum (Image 1). Females laid $8.67 \pm 0.67$ batches of eggs with a total number of $56.33 \pm 7.88$ eggs. The batch size varied from the mean minimum of $3.33 \pm 0.33$ per batch to the mean maximum of $11.33 \pm 1.45$ per batch. The fertilized eggs turn into dark reddish chorion with eyespots prior to hatching whereas unfertilized eggs become shrunken after a few days. The eggs hatched after $8.17 \pm 0.31 \mathrm{~d}$. The pre-oviposition period of $C$. gilvus was $11.00 \pm 0.37 \mathrm{~d}$ and females lived only $3.83 \pm 0.17 \mathrm{~d}$ (post-oviposition period) after laying its last batch of eggs (Table 1). The oviposition index value observed was $67.07 \%$.

The newly hatched nymphs were fragile and they became tanned in 3-4 hr after emergence and thereafter start feeding, showing preference to small and sluggish larvae. The developmental duration of I, II, III, IV and V instars were $9.50 \pm 1.45,6.33 \pm 0.33,4.50 \pm 0.62,6.00 \pm 0.68$ and $11.00 \pm 1.88 \mathrm{~d}$, respectively (Table 2). Survival percentage of first instar was comparatively lower than
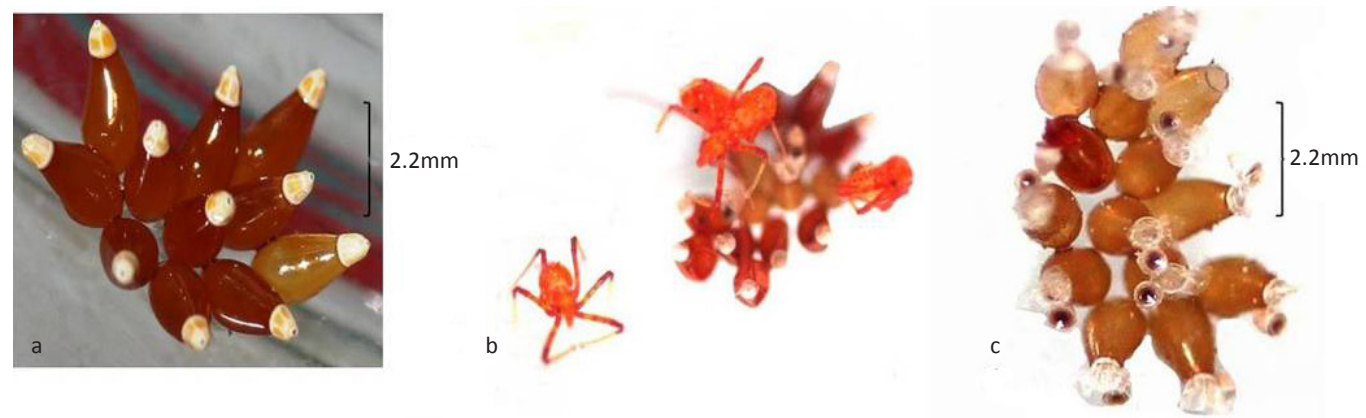

(c) K.K. Srikumar

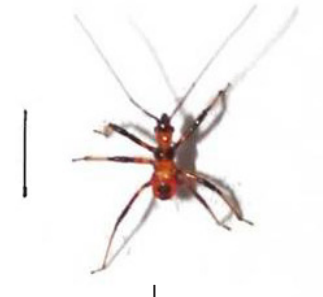

$(2.2 \mathrm{~mm})$

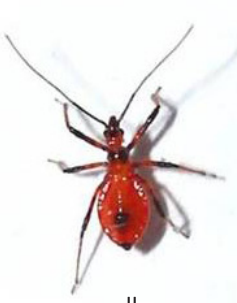

$(3.1 \mathrm{~mm})$

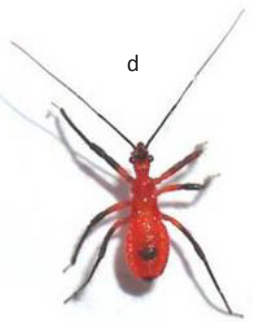
$(5.1 \mathrm{~mm})$

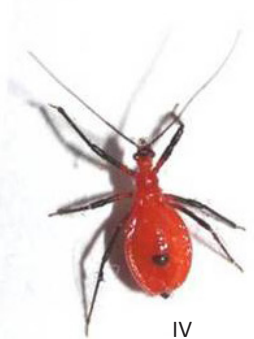

$(7.2 \mathrm{~mm})$

Image 1. Cydnocoris gilvus: (a) fresh eggs, (b) eggs hatching, (c) hatched eggs and (d) I-V nymphal instars 
Table 1. Longevity and oviposition pattern of $C$. gilvus $(n=45)$

\begin{tabular}{|l|l|}
\hline Parameters & C. gilvus (mean \pm SE) \\
\hline Adult male longevity (d) & $41.67 \pm 4.69$ \\
\hline Adult female longevity (d) & $42.00 \pm 4.98$ \\
\hline Pre-oviposition (d) & $11.00 \pm 0.37$ \\
\hline Post-oviposition (d) & $3.83 \pm 0.17$ \\
\hline Oviposition (d) & $28.17 \pm 4.47$ \\
\hline Oviposition index (\%) * & 67.07 \\
\hline Total number of batches of eggs & $8.67 \pm 0.67$ \\
\hline Total number of eggs laid (Fecundity) & $56.33 \pm 7.88$ \\
\hline Average number of eggs /batch & $6.44 \pm 0.99$ \\
\hline Minimum number of eggs / batch & $3.33 \pm 0.33$ \\
\hline Maximum number of eggs/ batch & $11.33 \pm 1.45$ \\
\hline Hatching percentage (\%) & $93.57 \pm 4.84$ \\
\hline
\end{tabular}

* Percentage of egg-laying days in total lifespan of female

Table 2. Incubation and developmental period of C. gilvus

\begin{tabular}{|l|c|c|}
\hline Parameters & Mean \pm SE $(\mathbf{n}=45)$ & Range (d) \\
\hline Incubation period (d) & $8.17 \pm 0.31$ & $7-9$ \\
\hline \multicolumn{2}{|l|}{ Stadial period (d)/ Per cent survival } \\
\hline I & $9.50 \pm 1.45(47.37)$ & $6-14$ \\
\hline II & $6.33 \pm 0.33(100.00)$ & $5-7$ \\
\hline III & $4.50 \pm 0.62(77.78)$ & $3-7$ \\
\hline IV & $6.00 \pm 0.68(100.00)$ & $3-8$ \\
\hline V & $11.00 \pm 1.88(85.00)$ & $7-20$ \\
\hline Male (d) & $38.00 \pm 3.00$ & $32-41$ \\
\hline Female (d) & $36.67 \pm 2.92$ & $31-41$ \\
\hline Total (d) & $37.33 \pm 0.67(82.17)$ & $31-41$ \\
\hline Sex ratio (M:F) & $1: 0.8$ & \\
\hline
\end{tabular}

Values in parentheses indicate the survival percentage.

other instars.

The developmental period of females was faster $(36.67 \pm 2.96 \mathrm{~d})$ than males $(38.00 \pm 3.00 \mathrm{~d})$ (Fig. 1). $C$. gilvus took $45.5 \pm 0.92$ days to complete a generation.

The innate capacity of natural increase ( $\mathrm{rc}$ ) was 0.07 with a gross reproduction $(\mathrm{mx})$ of 67.80 females per female. Mean length of generation (Tc) was 52.26 days (Table 3).

Predatory behaviour: C. gilvus exhibited a pin and jab mode of predation in a sequence of acts. The sequential action of predatory behaviour was observed in a span of $24 \mathrm{hr}$ as follows: arousal - approach - capturing - rostral probing - paralysing - sucking - postpredatory behaviour. The nymphs showed no cannibalistic behaviour when they were mass reared (Image 2).

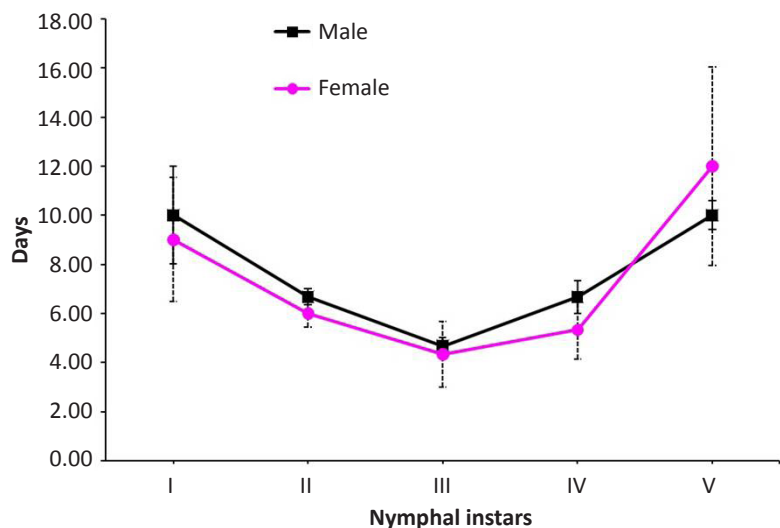

Figure 1. Developmental period of C. gilvus male and female (mean \pm SE)

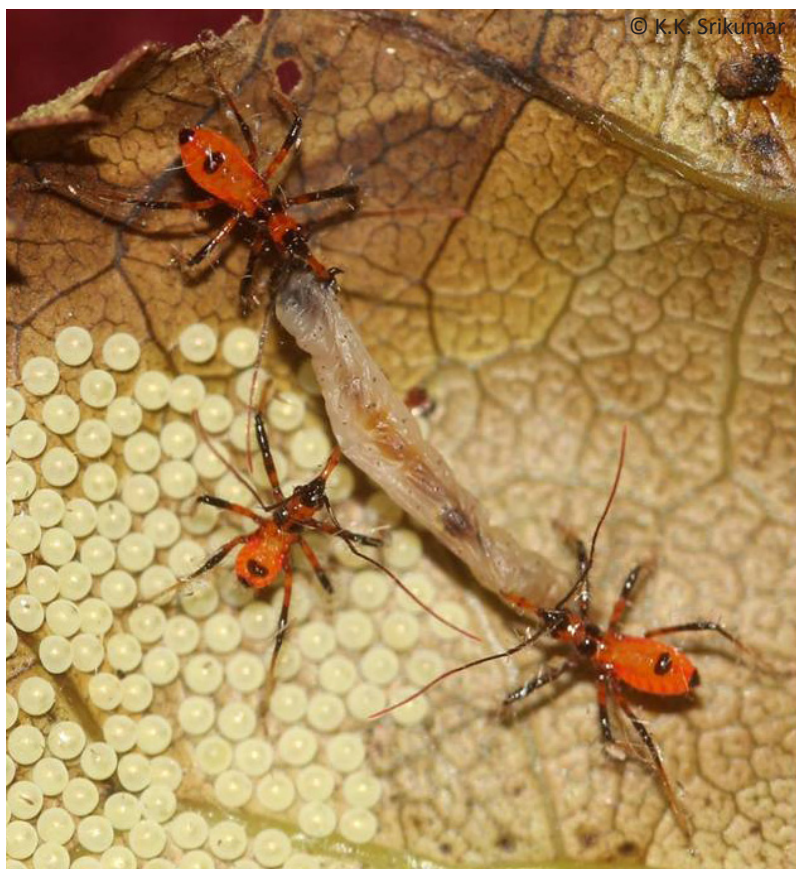

Image 2. C. gilvus nymphs predating on wax moth larva

Table 3. Life table parameters of Cydnocoris gilvus on G. mellonella under laboratory conditions

\begin{tabular}{|l|c|c|}
\hline Parameters & Formula & \\
\hline Gross reproduction (GR) (females/female/day) & $\sum \mathrm{mx}$ & 67.80 \\
\hline Net reproduction $\left(\mathrm{R}_{\mathrm{o}}\right)$ & $\sum \mathrm{lxmx}$ & 48.80 \\
\hline Mean length of generation $\left(\mathrm{T}_{\mathrm{c}}\right)$ & $\sum^{\mathrm{x} \times \mathrm{xm}} \mathrm{R}_{\mathrm{Ro}}$ & 52.26 \\
\hline $\begin{array}{l}\text { Innate capacity of increase in numbers }(\mathrm{rc}) \\
\text { (females/female/day) }\end{array}$ & loge $^{\mathrm{Ro}} / \mathrm{Tc}_{\mathrm{c}}$ & 0.07 \\
\hline Hypothetical $\mathrm{F}_{2}$ females & $(\mathrm{Ro})^{2}$ & 2381.44 \\
\hline
\end{tabular}


Table 4. Functional response of $C$. gilvus towards $H$. antonii

\begin{tabular}{|c|c|c|c|c|c|c|c|c|c|}
\hline $\begin{array}{l}\text { Prey density } \\
\text { (x) }\end{array}$ & $\begin{array}{c}\text { Prey } \\
\text { attacked } \\
\text { (y) }\end{array}$ & $\begin{array}{c}\text { Max ' } y^{\prime} \\
\text { (k) }\end{array}$ & $\begin{array}{l}\text { Days } / y \\
b=T t / k\end{array}$ & $\begin{array}{l}\text { All y's days } \\
\text { (by) }\end{array}$ & $\begin{array}{c}\text { Searching } \\
\text { days } \\
\text { Ts = Tt-by }\end{array}$ & $\begin{array}{c}\text { Attack ratio } \\
y / x\end{array}$ & $\begin{array}{c}\text { Rate of } \\
\text { discovery } \\
y / x / T s=\alpha\end{array}$ & $\begin{array}{c}\text { Disc } \\
\text { equation } \\
y^{\prime}=\alpha(T t- \\
\text { by) } x\end{array}$ & $y^{\prime}$ \\
\hline 1 & 0.48 & & & 0.92 & 4.08 & 0.48 & 0.12 & $\begin{array}{l}y^{\prime}=0.12 \\
(4.08) \times 1\end{array}$ & 0.49 \\
\hline 2 & 1.89 & 2.60 & 1.92 & 3.63 & 1.37 & 0.95 & 0.69 & $\begin{array}{l}y^{\prime}=0.69 \\
(4.08) \times 2\end{array}$ & 5.63 \\
\hline 4 & 2.40 & & & 4.62 & 0.38 & 0.60 & 1.56 & $\begin{array}{l}y^{\prime}=1.56 \\
(4.08) \times 4\end{array}$ & 25.46 \\
\hline 8 & 2.60 & & & 5.00 & 0.00 & 0.33 & - & - & \\
\hline
\end{tabular}
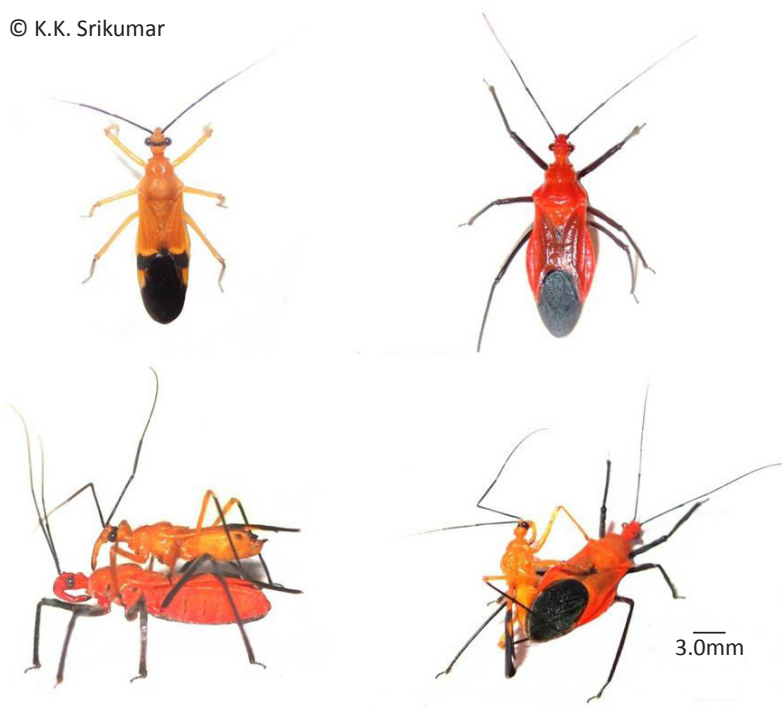

Image 3. C. gilvus: (a) male, (b) female, (c) riding over and (d) copulation

Mating behaviour: The sequential act of mating behaviour observed in $C$. gilvus as follows:

Arousal - approach - riding over - copulation - post copulatory acts: The matured $C$. gilvus adults (4-5 days old) were aroused immediately by the sight of the opposite sex in $1.32 \pm 0.29 \mathrm{~min}$. The aroused male chased the females within a span of $12.3 \pm 1.34$ min with extended antenna movement. Sometimes the females escaped from the approaching male. The male placed its legs on the female after approaching. Males rode over the females with extended rostrum for $140.48 \pm 5.48$ min. Riding over was seen longer than all other mating behaviors (Image 3c). Copulation was $85.40 \pm 2.99 \mathrm{~min}$ in duration. It remained motionless during copulation and exhibited pterothorax rostral pinning. Drooping down of antennae by both the sexes was observed at the termination of copulation and thereafter separation of mating partners. After separation both male and female moved away from the place of copulation (Image $3 d$ ). The post copulatory acts such as genitalia brushing, antennal grooming, cleaning the legs, and wing beating were observed in both sex partners. Post copulatory acts lasted for $5.70 \pm 0.37 \mathrm{~min}$. Successful completion of copulation was evidenced by the ejection of spermatophore capsule by female after termination of copulation.

Functional response: C. gilvus responded to increasing prey density by killing more prey than at lower prey densities (Table 4). The number of prey killed (y) by the individual predator increased as the prey density $(x)$ increased from one prey/predator to eight prey /predator. This was further confirmed by the positive correlation ( $r=0.63$ ) obtained between prey density and prey killed. The maximum predation was represented by ' $k$ ' value (2.60). The highest attack ratio was observed at the density of two prey/predator and the lowest attack ratio was found at the density of eight prey/predator. Hence, the attack ratio decreased as the prey density increased $(r=-0.63)$. A negative correlation was obtained between prey density and searching time ( $r=-0.35$ ) of the predator at all prey densities.

\section{DISCUSSION}

Biological studies on reduviids and their utilization in biological control of insect pests have been gaining momentum in India and other countries in recent years (Sahayaraj 2007; Schaefer 2010).

The laboratory culture technique standardized using wax moth larva as prey was found to be similar to the other reduviid rearing techniques (Vennison \& Ambrose 1990; Ambrose 1999; Ambrose 2000; Sahayaraj 2012).

C. gilvus laid eggs on the bottom and sides of the rearing bottles and muslin cloth as reported in Edocla slateri Distant (Vennison \& Ambrose 1986), Coranus soosaii Ambrose \& Vennison (Vennison 1989) and C. spiniscutis Reuter (Claver \& Reegan 2010). The fecundity of $C$. gilvus was higher than Sphedanolestes spp. (15.33 \pm 6.41 eggs) (Vennison \& Ambrose 1990) while lower than that of Rhynocoris marginatus Fab. 


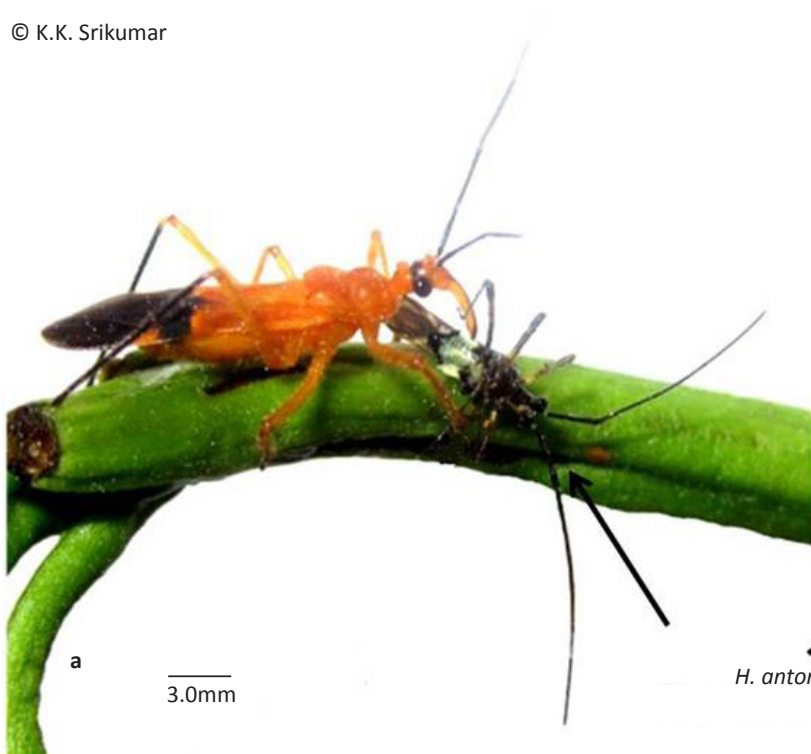

Image 4. C. gilvus: (a) male and (b) female predating on $\boldsymbol{H}$. antonii

(208.3 \pm 3.9 eggs) (Sahayaraj \& Sathiamoorthi 2002) and C. spiniscutis (173.72 \pm 11.67 eggs) (Claver \& Reegan 2010).

The egg incubation period was shorter than other harpactorines like R. kumarii (10 d), Sycanus collaris Fab. (15 d) and Panthous bimaculatus Dist. (21 d) (Sahayaraj 2012) and higher than R. marginatus (6-7 d) (Sahayaraj \& Sathiamoorthy 2002) and S. variabilis $(6.92 \pm 0.29$ d) (Ambrose et al. 2009). The longest stadium was the fifth instar and the shortest was the third instar. Harpactorines generally have the shortest stadial period for II and III instars (Das 1996).

The total nymphal developmental period of $C$. gilvus was closer to S. variabilis (37.33 $\pm 4.40 \mathrm{~d}$ ) (Ambrose et al. 2009) and shorter than that of $S$. collaris $(75.67 \pm 9.06), R$. kumarii $(88.30 \pm 3.60)$ and $P$. bimaculatus $(101.12 \pm 2.30)$ (Sahayaraj 2012). The higher mortality of first instar nymphs might be owing to a higher susceptibility to mechanical injuries and temperature variations.

The male biased sex ratio was observed in harpactorines as well as nonharpactorine reduviids (Ambrose 1999; Ambrose et al. 2007).

The sequential pattern of pin and jab mode of predation observed in C. gilvus was similar to that of several other harpactorine reduviids (Ambrose 1999). Congregational feeding and cannibalism observed in many reduviids (Das \& Ambrose 2008) were not observed in $C$. gilvus when they were mass reared. Though cannibalism is common among adults and nymphs, the degree of intensity of such behaviour vary considerably among different subfamilies and species
(Ambrose 1999).

Mating behaviour was reported in Ectomocoris tibialis Dist. and Acanthespis pedestris Stal (Ambrose \& Livingstone 1978), Rhynocoris kumarii (Ambrose \& Livingstone 1987a) and Coranus vitellinus Dist. (Ambrose \& Livingstone 1987b). The duration of riding over was significantly longer than arousal, approach and copulation. C. gilvus mated in dorsoventral position as reported in Sycanus reclinatus Doh. and Coranus soosaii Ambrose \& Vennison (Vennison 1989) and in several other harpactorine reduviids (Ambrose 1999).

The number of prey killed ( $y$ ) by the individual predator increased as the prey density $(x)$ increased, thus exhibiting the typical functional response of the second model of Holling's 'disc' equation (1959). The type II functional response is typical for most heteropteran predators (Cohen \& Byrne 1992). Awadallah et al. (1984) working on Allaeocranum biannulipes Montr. of a stored product pest, Ambrose et al. (2000) on $R$. marginatus of a pest of pigeon peas and Claver et al. (2004) on C. spiniscutis Reut. Spodoptera litura Fab. and Helicoverpa armigera Hub. (Noctuidae: Lepidoptera) observed a similar response. An indirectly proportional relationship was found between the attack ratio and the prey density which is similar to the results obtained by Ambrose et al. (2009) in S. variabilis. It is assumed that when the prey density increases, predator took less time on nonsearching activities, resulting in discerning decline in attack rate until the hunger is established (Claver et al. 2004). A negative correlation was also obtained between prey density and searching time as 
the results of Ambrose et al. (2009).

In conclusion the study suggested that $C$. gilvus can be multiplied within 50 days for a generation in the laboratory. Cannibalistic behaviour was not observed, which is ideal for the mass culture of this predator. The present study on the functional response suggested that C. gilvus is capable of reducing pest numbers (Image 4). However, the efficacy of $C$. gilvus in biocontrol of Helopeltis spp. needs further investigation.

\section{REFERENCES}

Ambrose, D.P. (1999). Assassin Bugs. New Hampshire, USA: Science publishers and New Delhi, India. Oxford and IBH Publ. Co. Pvt. Ltd., 337pp.

Ambrose, D.P. (2000). Substrata impact on mass rearing of the reduviid predator Rhynocoris kumarii Ambrose and Livingstone (Heteroptera: Reduviidae). Journal of Entomological Research 24: 337-342.

Ambrose, D.P. (2003). Biocontrol potential of assassin bugs (Hemiptera: Reduviidae). Journal of Experimental Zoology 6: 1-44.

Ambrose, D.P. \& D. Livingstone (1978). On the mating behaviour of Ectomocoris tibialis Distant and Acanthaspis pedestris Stal two reduviids of the scrub jungles of Palghat gap. Journal of Madras University 41: 69-79.

Ambrose, D.P. \& D. Livingstone (1979). On the bioecology of Lophocephala guerini Laporte. (Reduviidae: Harpactorinae) a coprophagous reduviid from Palghat gap. Journal of Natural History 13: $581-588$

Ambrose, D.P. \& D. Livingstone (1987a). Mating behaviour and impact of mating on oviposition pattern and hatchability in Rhinocoris kumarii. Environment and Ecology 5: 156-161; http://dx.doi. org/10.1002/mmnz.19910670210

Ambrose, D.P. \& D. Livingstone (1987b). Mating behaviour of Coranus vitellinus Distant (Insecta: Heteroptera: Reduviidae), pp. 22-26. In: Ismail, A. \& S.S. Alaedeen (eds). Aspects of Behaviour. New College, Madras.

Ambrose, D.P., S.K. Gunaseelan, J.V. Singh, B. Ravichandran \& K. Nagarajan (2007). Redescription, biology and behaviour of a harpactorine assassin bug Endochus migratorius Distant. Hexapoda 14: $12-21$

Ambrose, D.P., S.P. Kumar, K. Nagarajan, S.M. Das \& B. Ravichandran (2006). Redescription, biology, life table, behaviour and ecotypic diversity of Sphedanolestes minusculus Bergroth (Hemiptera: Reduviidae). Entomologia Croatia 10: 47-66.

Ambrose, D.P., S.J. Rajan, K. Nagarajan \& S.S. Krishnan (2009). Biology, behaviour and functional response of Sphedanolestes variabilis Distant (Insecta: Hemiptera: Reduviidae: Harpactorinae), a potential predator of lepidopteran pests. Entomologia Croatia 13: 33-44.

Atwal, A.S. \& S.S. Brains (1974). Applied Animal Ecology. Kalyani Publishers, Ludhiana, 177-179pp.

Awadallah, K.T., M.F.S. Tawfik \& M.M.H. Abdellah (1984) Suppression effect of the reduviid predator, Allaeocranum biannulipes (Montr. Er. Sign.) on populations of some stored product insect pests. Journal of Applied Entomology 97: 249-253; http://dx.doi.org/10.1111/j.1439 0418.1984.tb03745.x

Claver, M.A. \& A.D. Reegan (2010). Biology and mating behaviour of Coranus spiniscutis Reuter (Hemiptera: Reduviidae), a key predator of rice gandhi bug, Leptocorisa varicornis Fabricius. Journal of Biopesticides 3: 437-440.

Claver, M.A., M.S.A. Muthu, B. Ravichandran \& D.P. Ambrose (2004). Behaviour, prey preference and functional response of Coranus spiniscutis (Reuter), a potential predator of tomato insect pests. Pest Management in Horticultural Ecosystem 10: 19-27.
Cohen, A.C. \& D.W. Byrne (1992). Geocoris punctipes and predator of Bemisia tabacci, a laboratory evaluation. Entomologia Experimentalis et Applicata 64: 195-202; http://dx.doi. org/10.1111/j.1570-7458.1992.tb01609.x

Das, S.S.M (1996). Biology and behaviour of chosen predatory hemipterans. PhD Thesis. Madurai Kamaraj University, Madurai, India, 201pp.

Das, S.S.M. \& D.P. Ambrose (2008). Rediscription biology and behaviour of the harpatocorine Assassin Bug Irantha armipes (Stal) (Hemiptera: Reduviidae). Acta Entomologica Slovenica 16: 37-56.

Devasahayam, S. \& C.P.R. Nair (1986). The Mosquito Bug, Helopeltis antonii Sign. on cashew in India. Journal of Plantation Crops 14: $1-10$.

DCCD (Directorate of Cashewnut and Cocoa Development) (2013). The Cashew and Cocoa Journal 2: 37-38.

DCR (Directorate of Cashew Research) (2011). Vision 2030. 22pp.

FAO (Food and Agriculture Organization) (2011). http://faostat3.fao. org/faostat-gateway/go/to/download/Q/QC/E.

Holling, C.S. (1959). Some characteristics of simple types of predation and parasitism. Canadian Entomologist 91: 385-398; http://dx.doi. org/10.4039/Ent91385-7

Rao, V.P., M.A. Ghani, T. Sankaran \& K.C. Mathur (1971). A review of the biological control of insects and other pests in Southeast Asia and the Pacific region (CIBC Technical communications No. 6, Commonwealth Agricultural Bureaux Farnham Royal, U.K., 2437pp.

Sahayaraj, K. (2007). Pest Control Mechanism of Reduviids. Oxford Book Co. University of Chicago, 240pp.

Sahayaraj, K. (2012). Artificial rearing on the nymphal developmental time and survival of three reduviid predators of Western Ghats, Tamil Nadu. Journal of Biopesticides 5: 218-221.

Sahayaraj, K. \& P. Sathiamoorthi (2002). Influence of different diets of Corcyra cephalonica on life history of a reduviid predator Rhynocoris marginatus (Fab.). Journal of Central European Agriculture 3: 53-62.

Sahayaraj, K., P. Martin, C. Selvaraj \& M. Raju (2006). Artificial diets on the predatory behaviour of Rhynocoris marginatus (Fab.) (Hemiptera: Reduviidae). Belgium Journal of Entomology 8: 55-65.

Schaefer, C.W. \& P.A. Ricardo (2010). Heteroptera of Economic Importance. CRC press, $856 \mathrm{pp}$.

Stonedahl, G.M. (1991). The oriental species of Helopeltis (Heteroptera: Miridae): a review of economic literature and guide to identification. Bulletin of Entomological Research 81: 465-490; http://dx.doi.org/10.1017/S0007485300032041

Sundararaju, D. (1984). Cashew pests and their natural enemies in Goa. Journal of Plantation Crops 12: 38-46.

Sundararaju, D. (1993). Compilation of recently recorded and some new pests of cashew in India. The Cashew 7: 15-19.

Sundararaju, D. (1996). Studies on Helopeltis spp. with special reference to $H$. antonii Sign. in Tamil Nadu. PhD Thesis. T.N.A.U., Coimbatore, India, 210pp.

Sundararaju, D. \& N.J. John (1992). Mass rearing technique for Helopeltis antonii (Heteroptera: Miridae) - an important pest of cashew. Journal of Plantation Crops 20: 46-53.

Venkatesan, S., R. Sreenivasagan \& G. Karuppasamy (1997). Influence of prey species on feeding response, development and reproduction of the reduviid, Cydnocoris gilvus Burm. (Reduviidae: Heteroptera). Entomon 22: 21-27.

Vennison, S.J. (1989). Bioecology, ecophysiology and ethology of chosen assassin bugs, PhD Thesis. Madurai Kamaraj University, Madurai, 211pp.

Vennison, S.J. \& D.P. Ambrose (1986). Bioecology of a dimorphic Assassin Bug, Edocla slateri Distant (Heteroptera: Reduviidae). Entomon 11: 255-258.

Vennison, S.J. \& D.P. Ambrose (1990). Biology and behaviour of Sphedanolestes signatus Distant (Insecta: Heteroptera: Reduviidae) a potential predator of Helopeltis antonii Signoret. Uttar Pradesh Journal of Zoology 10: 30-43.

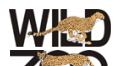

